\title{
TERAPI KOGNITIF PERILAKU UNTUK MENURUNKAN TINGKAT KECEMASAN PADA KLIEN DENGAN GANGGUAN AGORAFOBIA
}

\section{COGNITIVE BEHAVIOR THERAPHY TO REDUCE ANXIETY LEVEL IN CLIENTS WITH AGOROPHOBIA DISORDER}

\author{
Yunita Victoria Natal \\ Magister Psikologi Profesi, Universitas 17 Agustus 1945 Surabaya \\ yuninata196@gmail.com
}

Received: $5^{\text {th }}$ January 2021; Revised: $21^{\text {st }}$ Januari 2020; Accepted: $2^{\text {nd }}$ February 2021

\begin{abstract}
Agoraphobia is a condition where individuals experience being in a certain situation or place. This study aims to reduce victims of agoraphobia through behavioral therapy. This therapy aims to invite the client to the wrong emotion and group by presenting evidence that contradicts beliefs about the problem at hand. The method in research using a single case study. Data were collected through interview methods, observation and psychological tests in the form of graphic tests, WWQ and IST. The subject in this study was a 21 years old teenager and male. The therapy was given in 3 main stages, the initial stage, the middle stage and the final stage, which was carried out for 4 weeks with each session lasting 1.5 hours. Result showed that clients can go to public places by themselves, be independent of other people when traveling alone, have more confidence and build relationships with people around them and do not experience shortness of breath when in a crowd.
\end{abstract}

Keywords: Agoraphobia Disorder, Anxiety, Behavioral Cognitive Therapy

\begin{abstract}
ABSTRAK
Agorafobia merupakan suatu kondisi dimana individu mengalami kecemasan ketika berada dalam suatu situasi atau suatu tempat tertentu. Penelitian ini bertujuan untuk menurunkan kecemasan penderita gangguan Agorafobia melalui terapi kognitif perilaku. Terapi ini bertujuan untuk mengajak klien menentang pikiran dan emosi yang salah dengan menampilkan bukti-bukti yang bertentangan dengan keyakinan tentang masalah yang dihadapi. Metode dalam penelitian ini menggunakan single case study. data dikumpulkan melalui metode wawancara, observasi dan tes psikologi berupa tes Grafis, WWQ dan IST. Subjek dalam penelitian ini merupakan seorang remaja berusia 21 tahun dan berjenis kelamin laki-laki. Pemberian terapi diberikan melalui 3 tahap utama yakni tahap awal, tahap pertengahan dan tahap akhir yang dilakukan selama 4 minggu dengan masing-masing sesi dilakukan selama 1,5 jam. Berdasarkan hasil intervensi yang telah dilakukan klien dapat pergi ke tempat umum sendiri, tidak bergantung dengan orang lain saat berpergian sendiri, lebih percaya diri dan menjalin relasi dengan orang di sekitar dan tidak mengalami sesak napas saat berada di keramaian.
\end{abstract}

Kata Kunci : Gangguan Agorafobia, Kecemasan, Terapi kognitif perilaku 


\section{PENDAHULUAN}

Dalam menjalani kehidupan sehari-hari, perilaku manusia dapat bersumber melalui kekuatan irasional dan rasional yang mana kekuatan tersebut merupakan respon terhadap stimulus yang didapatkan melalui lingkungannya. Stimulus yang diserap oleh individu dari lingkungannya kemudian diinternalisasikan dengan proses berpikir yang menyebabkan suatu keyakinan baik keyakinan secara rasional maupun irasional. Ketika keyakinan irasional terus berkembang dalam diri individu maka akan mempengaruhi munculnya perilaku maladaptif yang akan merugikan dirinya sendiri maupun orang di sekitarnya.

Salah satu perilaku yang ditimbulkan oleh keyakinan irasional adalah perilaku orang yang mengalami gangguan agorafobia. Istilah agorafobia berasal dari Bahasa yunani yang artinya "takut terhadap tempat-tempat belanja". Orang yang mengalami gangguan agorafobia cenderung mengalami ketakutan pada kerumunan dan dan tempat-tempat ramai. Selain itu, mereka juga mengalami ketakutan ketika berada pada ruang sempit, takut pada tempat luas dan terbuka, terlebih saat mereka sendirian. Wiramihardja (2005) memberikan arti serupa tentang agorafobia, yaitu suatu ketakutan berada dalam suatu tempat atau situasi dimana ia merasa bahwa ia tidak dapat atau memiliki kekurangan baik secara fisik maupun psikis. penderita agorafobia cenderung mengalami kecemasan ketika berada di suatu lingkungan yang asing atau suatu tempat dimana ia merasa tidak nyaman seperti pada ruang terbuka, keramaian atau saat berpergian (Yaunin,2012)

Penderita gangguan agorafobia menunjukan berbagai macam keadaan atau gejala-gejala yang menyertai sebagai berikut : 


\section{a. Panic Disorder}

Pada keadaan ini penderita agorafobia menunjukan satu atau dua serangan panic dimana keadaan panic tersebut bukan merupakan suatu masalah yang luar biasa bagi orang lain, bukan hal yang menakutkan dan wajar terjadi. Keadaan ini biasanya diikuti dengan gejala nafas yang pendek, palpilasi (mulut kering), ketakutan akan mati atau takut gila. Menurut DSM IV (American Psychiatri Association,2000) jika seseorang merasakan khawatir akan serangan panic dan mengalami perubahan perilaku sebagai akibat dari kekhawatiran tersebut maka orang tersebut dapat didiagnosis mengalami serangan panik. Simtom serangan panik biasanya ditandai dengan jantung berdebar-debar, mengalami mati rasa atau kehilangan sensasi geli, mengalami panas atau dingin, berkeringat, gemetaran atau bergncang, sensasi nafas yang pendek, merasa cekikan, dada terasa nyeri atau tidak nyaman, mual atau perut terasa tidak enak, pusing-pusing, mata kunang-kunang, merasa asing, takut kehilangan kontrol atau menjadi gila, takut akan mati.

\section{b. Obsesive-compulsive}

Selain panic disorder, obsesi-kompulsif juga merupakan salah satu jenis atau kriteria agorafobia. Obsesif menyangkut pikiran sedangkan kompulsif menyangkut tindakan. Obsessive-Compulsive Disorder (OCD) diklasifikasikan sebagai suatu gangguan karena orang dengan gangguan OCD mengalami kecemasan yang merupakan manifestasi dari pikiran-pikiran obsesif dan pikiran tersebut tidak dapat dikendalikan oleh perilaku kompulsif mereka (Hamidah \& Syafaatul, 2017). OCD dapat menjadi gangguan kronis jika 
tidak diobati segera atau tidak ditangani pikiran-pikiran obsesif tersebut karena akan semakin menimbulkan perilaku berbahaya, baik untuk dirinya sendiri maupun orang lain.

\section{c. Generalisation Anxiety Disorder}

Gangguan kecemasan yang tergeneralisasikan ditandai oleh adanya rasa khawatir yang kronis. Bentuk fobia dan agorafobia termasuk dalam periode anxiety yang akut atau hanya sebentar. Orang dengan GAD khawatir terhadap berbagai hal dalam kehidupannya, seperti kecemasan dan kekhawatiran yang eksesif, sulit berkonsentrasi, pikiran kosong, mudah tersinggung dan mengalami gangguan tidur. Selain itu kondisi fisik yang ditampilkan berupa sakit kepala, jantung berdebar, kelelahan, sesak nafas, dll (Sutarjo,2005).

Penegakkan diagnosis agoraphobia dilakukan berdasarkan kriteria diagnostik psikiatri DSM-5 (2013), kriteria diagnostik untuk agorafobia, yaitu memiliki ketakutan berlebih atau kecemasan yang dipicu oleh paparan yang pasti atau dapat diprediksi pada 2 atau lebih situasi berikut:

1. Menggunakan transportasi publik.

2. Berada di area terbuka.

3. Berada di area tertutup.

4. Berdiri dalam antrian atau keramaian.

5. Keluar sendirian dari rumah.

6. Pengidap menghindari situasi di atas karena yakin akan merasa terjebak atau tidak dapat meminta bantuan ketika dia mengalami serangan panik.

7. Situasi-situasi di atas selalu menyebabkan panik atau cemas.

8. Situasi-situasi di atas dihindari, membutuhkan pertolongan dari orang terdekat, ataupun akan mengidap ketakutan yang sangat kuat. 
9. Ketakutan yang dialami lebih besar dari kemungkinan bahwa bahaya akan terjadi.

10. Ketakutan yang dialami atau upaya menghindari (avoidance) terjadi terus-menerus, berlangsung selama 6 bulan atau lebih.

11. Ketakutan yang dialami atau upaya menghindari (avoidance) menyebabkan penderitaan yang signifikan.

12. Jika ada kondisi medis lain terjadi (selain gangguan ini), maka ketakutan atau upaya menghindari (avoidance) akan semakin berlebih.

13. Ketakutan yang dialami atau upaya menghindari (avoidance) tidak dapat dijelaskan oleh gangguan medis lain.

Penyebab seseorang mengalami agorafobia belum diketahui secara pasti, namun gangguan ini diduga terjadi akibat adanya riwayat gangguan panik terdahulu, gangguan cemas dengan disertai kepanikan dan pada situasi yang memicu ketakutan yang berlebihan. Gangguan panik ini kemungkinan terjadi dikarenakan adanya riwayat keluarga dengan gangguan serupa atau adanya kejadian traumatik atau stressor sebelumnya. Untuk mengatasi gangguan ini terdapat berbagai langkah yang dilakukan antara lain melalui pengobatan maupun terapi perilaku. Salah satu terapi psikologi yang dapat membantu menyembuhkan pasien agorafobia adalah terapi kognitif. Terapi ini merupakan kombinasi dua pendekatan terapi yakni kognitif dan perilaku. Terapi ini berusaha untuk mengintegrasi teknik-teknik terapeutik yang berfokus untuk membantu individu melakukan perubahan-perubahan, tidak hanya perilaku nyata tetapi juga dalam pemikiran, keyakinan dan sikap yang mendasarinya. Terapi kognitif perilaku memiliki asumsi bahwa pola pikir dan keyakinan mempengaruhi perilaku, dan perubahan pada kognisi tersebut dapat menghasilkan perubahan perilaku yang diharapkan. Sesi-sesi dalam tahapan 
terapi kognitif perilaku memiliki tujuan yakni : 1) membantu klien untuk memulihkan aktivitas hariannya sebagai dasar dan arah terapi secara bertahap, 2) mendorong klien untuk mengidentifikasi dan menentang pikiran negatif agar dapat menemukan pikiran yang realistis dan rasional. 3) membantu pasien agar mampu menjalankan rutinitas dan aktivitas sehari-hari secara produktif.

\section{METODE PENELITIAN}

Desain dalam penelitian ini menggunakan subjek tunggal (single case design) dengan bentuk desain eksperimen A-B-A yang digambarkan sebagai berikut:

\section{Gambar 1. Desain Eksperimen Kasus Tunggal A-B-A}

\section{O1 X O2}

Desain A-B-A menggambarkan tiga fase dalam penelitian ini yakni fase A (baseline 1) yang merupakan kondisi subjek sebelum diberikan intervensi, fase B (perlakuan) merupakan fase pemberian intervensi berupa terapi kognitif behavior dan fase A (baseline 2) yaitu fase setelah intervensi diberikan. Pengukuran dilakukan pada sebelum, saat dan sesudah (Hastjarjo,2019).

Subjek dalam penelitian ini adalah seorang remaja putri berusia 21 tahun dan didiagnosa mengalami Agorafobia. Dalam penelitian ini menggunakan instrument tes berupa tes psikologi : Tes IST yang bertujuan untuk mengetahui taraf inteligensi yang dimiliki klien, Tes Grafis yang bertujuan untuk mengetahui kepribadian klien dan kemungkinan munculnya indikasi klinis yang tampak pada diri klien dan Tes WWQ yang bertujuan untuk mengetahui gejala patologis yang 
dimiliki klien. Prosedur dalam penelitian ini melalui 7 sesi dengan rincian kegiatan setiap sesi sebagai berikut:

Tabel 1. Rincian kegiatan proses terapi

\begin{tabular}{|c|c|c|}
\hline Sesi & Kegiatan & Tujuan \\
\hline I & Building rapport dan kontrak terapi & $\begin{array}{l}\text { Membangun kepercayaan klien sehingga adanya } \\
\text { keterbukaan antara klien dan terapis serta } \\
\text { menerangkan aturan-aturan yang dijalankan } \\
\text { selama proses terapi. }\end{array}$ \\
\hline II & Psikoedukasi dan Home assignment & $\begin{array}{l}\text { Memberikan pemahaman kepada klien terkait } \\
\text { hasil asesmen dan latar belakang pembentuk } \\
\text { pikiran irasional yang dimiliki klien.Pada sesi ini } \\
\text { terapis juga memberikan tugas rumah berupa } \\
\text { simple tought record, klien bertugas untuk } \\
\text { mencatat setiap kejadian yang dialami dan } \\
\text { perasaan yang muncul pada kejadian tersebut } \\
\text { selama satu minggu. }\end{array}$ \\
\hline III & $\begin{array}{l}\text { Identifikasi distorsi kognitif dan } \\
\text { konfrontasi }\end{array}$ & $\begin{array}{l}\text { Terapis bersama klien membahas tugas rumah } \\
\text { yang diberikan pada sesi sebelumnya untuk } \\
\text { membantu menemukan distorsi kognitif yang } \\
\text { dimiliki klien dan melakukan konfontasi } \\
\text { terhadap pikiran-pikiran irasional yang ada. }\end{array}$ \\
\hline IV & Restrukturisasi Kognitif & $\begin{array}{l}\text { Terapis bersama klien merestrukturisasi kembali } \\
\text { pikiran-pikiran irasional yang dimiliki dan } \\
\text { diungkapkan klien pada sesi sebelumnya agar } \\
\text { menjadi pikiran yang lebih rasional. }\end{array}$ \\
\hline V & Behavioral Experiment 1 & $\begin{array}{l}\text { Terapis meminta klien untuk mencoba } \\
\text { menerapkan teknik rekstrukturisasi kognitif } \\
\text { yang telah diajarkan sebelumnya untuk melihat } \\
\text { sejauh mana pengaruh teknik restrukturisasi } \\
\text { memberikan pengaruh terhadap klien dalam } \\
\text { menjalankan kehidupan sehari-hari. Pada sesi ini } \\
\text { klien mencoba untuk berpergian sendiri ke } \\
\text { tempat keramaian. }\end{array}$ \\
\hline VI & Behavioral Experiment 2 & $\begin{array}{l}\text { Terapis bersama klien mengevaluasi percobaan } \\
\text { yang telah dilakukan dan membahas hasilnya, } \\
\text { terapis juga memberikan penguatan pada klien. } \\
\text { Pada sesi ini klien kembali mencoba untuk } \\
\text { berpergian sendiri ke tempat keramaian dengan } \\
\text { jumlah orang di sekitar lebih banyak. }\end{array}$ \\
\hline VII & Evaluasi. & $\begin{array}{l}\text { Terapis bersama klien mengevaluasi rangkaian } \\
\text { proses terapi yang telah dilakukan. }\end{array}$ \\
\hline
\end{tabular}


Teknik analisis dalam penelitian ini ialah menggunakan teknik deskriptif terhadap perubahan tingkah laku klien yang diamati sebelum, selama dan setelah proses intervensi berlangsung.

\section{HASIL PENELITIAN}

Hasil penelitian telah dianalisis dengan membedakan berdasarkan waktu intervensi, yaitu sebelum intervensi, selama intervensi dan sesudah intervensi. Hasilnya bisa dilihat pada tabel dibawah ini:

\section{Tabel 2. Hasil Intervensi}

\begin{tabular}{|c|c|c|}
\hline Sebelum Intervensi & Selama Intervensi & Sesudah Intervensi \\
\hline \multirow[t]{4}{*}{$\begin{array}{l}\text { Klien memiliki pemikiran bahwa } \\
\text { "Ketika berada di tempat } \\
\text { keramaian atau berpergian } \\
\text { sendiri ia akan mengalami sesak } \\
\text { nafas dan hal tersebut sangat } \\
\text { memalukan sehingga ia ingin } \\
\text { menghindar saat keramaian dan } \\
\text { meminta bantuan pada orang lain } \\
\text { untuk menemaninya". }\end{array}$} & $\begin{array}{l}\text { Melakukan konfrontasi terhadap } \\
\text { distorsi kognitif yang dialami } \\
\text { dan merestrukturisasi kembali } \\
\text { pikiran-pikiran yang salah. }\end{array}$ & $\begin{array}{l}\text { Klien menemukan pemikiran yang salah dan } \\
\text { merubahnya menjadi pikiran yang rasional } \\
\text { bahwa : } \\
\text { 1. Kejadian pada bulan agustus } 2018 \text { bukan } \\
\text { suatu hal yang buruk dan kejadian } \\
\text { tersebut bisa dialami oleh siapapun. } \\
\text { 2. Rasa takut dan cemas merupakan hasil } \\
\text { dari persepsi yang salah atas kejadian } \\
\text { yang dialaminya. } \\
\text { 3. Ia tidak menemukan satupun kebenaran } \\
\text { tentang ketakutan yang dialami karena } \\
\text { ketika ia berpegian sendiri dan di tempat } \\
\text { umum ia tidak mengalami sesak nafas. } \\
\text { 4. Ia tidak dapat terus bergantung pada } \\
\text { orang lain karena orang lain tidak selalu } \\
\text { ada didekatnya. }\end{array}$ \\
\hline & $\begin{array}{l}\text { Klien berpergian sendiri ke } \\
\text { rumah doa dengan jumlah orang } \\
\text { di sekitar } 5-10 \text { orang. }\end{array}$ & $\begin{array}{l}\text { Klien mengatakan masih ada sedikit } \\
\text { perasaan takut dan ingin segera pulang, } \\
\text { hanya saja ia tidak merasakan sesak napas. }\end{array}$ \\
\hline & $\begin{array}{l}\text { Klien pergi ke supermarket } \\
\text { dengan jumlah di sekitar } 10-15 \\
\text { orang III. }\end{array}$ & $\begin{array}{l}\text { Klien mengatakan bahwa ia merasa lebih } \\
\text { nyaman walaupun masih ada sedikit } \\
\text { ketakutan. }\end{array}$ \\
\hline & $\begin{array}{l}\text { klien pergi menyetor keuangan } \\
\text { sekolah di bank dengan jumlah } \\
\text { orang di sekitar } 15-25 \text { orang }\end{array}$ & $\begin{array}{l}\text { Klien merasa lebih tenang dan mampu } \\
\text { mengatasi ketakutan yang ada dengan } \\
\text { mengikuti teknik restrukturisasi yang telah } \\
\text { diajarkan }\end{array}$ \\
\hline
\end{tabular}




\section{DISKUSI}

Klien memiliki gangguan agorafobia yang ditandai oleh perilaku klien yang merasa ketakutan jika akan mengalami sesak nafas ketika berada di tempat keramaian atau berpergian sendiri sehingga ia sering menghindar pada situasi keramaian dan meminta bantuan pada orang lain untuk menemaninya dan terjadi selama kurang lebih 1 tahun. Berdasarkan PPDGJ III (maslim, 2013) seseorang ditetapkan memiliki gangguan agorafobia jika memenuhi kriteria berikut : 1) Gejala psikologis, perilaku atau otonomik yang timbul harus merupakan manifestasi primer dari anxietasnya dan bukan sekunder dari gejala-gejala lain. 2) Anxietas yang timbul harus terbatas pada (terutama terjadi dalam hubungan dengan) setidaknya dua dari situasi berikut: banyak orang/keramaian, tempat umum, berpergian keluar rumah dan berpergian sendiri. 3) Menghindari situasi fobik atau sudah merupakan gejala yang menonjol.

Individu yang terus menerus dalam ketakutan dan kecemasan, maka perasaannya akan terus menjadi perusak dirinya sendiri (self-defeating) dan menjadi tingkah laku yang irasional (Darsana, 1986). Menurut Beck tahun 1976 bahwa pemikiran manusia terbentuk melalui proses rangkaian stimulus-kognisi-respon yang saling berkaitan dan menentukan seseorang untuk bertindak, berpikir dn merasa. Pemikiran yang dimiliki oleh klien bahwa akan mengalami sesak nafas ketika berada di keramaian merupakan respon terhadap stimulus yang membentuk cara berpikir yang irasional sehigga pemikiran tersebut dimanifestasikan melalui perilaku yang ditunjukan oleh klien. Perilaku tersebut merupakan perilaku maladaptif karena menganggu ia dan lingkungannya dalam menjalankan kehidupan sehari-hari.

Terapi kognitif perilaku berusaha untuk mengintegrasi teknik-teknik terapeutik yang berfokus untuk membantu individu dalam melakukan perubahan-perubahan dalam pemikiran, 
keyakinan dan sikap. Tahapan-tahapan terapi kognitif perilaku menurut Susana (2015) secara bertahap dengan tujuan sebagai berikut:

1. Klien mengungkapkan pikiran-pikiran irrasional dan dapat membantah pikiran-pikiran tersebut menjadi pikiran yang rasional.

2. Klien dapat memiliki kesadaran merusak kebiasaan berpikir, menentang pikiran negatif serta mengganti pikiran untuk lebih meningkatkan kualitas hidup dan keyakinan yang dimiliki.

3. Klien berani mencoba berada pada situasi tesebut dan menerapkan teknik restrukturisasi yang telah diajarkan.

4. Klien dapat mengaplikasikan teknik restrukturisasi yang telah diajakan ketika klien berada pada situasi tertentu yang memunculkan pikiran irasionalnya.

Melalui pendekatan dalam tahapan intervensi di atas maka dapat memberikan perubahan pada pola piker dan perilaku klien dengan ditandai adanya kesadaran dari klien tentang pemikiran irrasional dan menggantikan pikiran irasional tersebut dengan pikiran rasional dan pemikiran rasion al klien tersebut mempengaruhi perilaku klien dimana ia menjadi lebih berani untuk berada di keramian sendiri, mulai dengan jumlah orang berkisar 5 -10 orang, mengalami peningkatan menjadi 10-15 orang dan 15 sampai 20 orang.

\section{KESIMPULAN DAN SARAN}

Simpulan yang dapat diperoleh dari penelitian ini adalah adanya pengaruh pemberian terapi kognitif perilaku dalam menurunkan kecemasan pada klien yang mengalami gangguan agorafobia. 
Berdasarkan hasil penelitian, saran yang diberikan kepada klien untuk yaitu mempertahankan perubahan perilaku yang telah ditunjukan secara konsisten dengan menerapkan teknik restrukturisasi yang telah dilakukan. Bagi keluarga dan orang di sekitar klien seperti keluarga atau teman-teman perlu memberikan dukungan berupa penguatan positif terhadap perubahan perilaku yang dilakukan klien dan menyediakan lebih banyak waktu bersama klien.

\section{DAFTAR PUSTAKA}

American Psychiatric Association. (2000). Diagnostic and Statistical Manual of Mental Disorders (DSM IV). Text Revised. Washington, DC: American Psychiatric Press, Inc.

American Psychiatric Association. (2013). Diagnostic and Statistical Manual of Mental Disorder Edition (DSM-V). Washington: American Psychiatric Publishing.

Beck, A.,T. (1976). Cognitive Therapy and the Emotional Disorders. New York: International Universities Press.

Hamidah.,\& Syafaatul.,L.(2017). Hubungan Antara Dukungan Sosial Dan Obsessive Compulsive Disorder pada Remaja Putri Dengan Kecenderungan Body Dysmorphic Disorder. Jurnal Psikologi Klinis dan Kesehatan Mental,6,71-80. Diunduh dari : http://url.unair.ac.id/3cb97dc0

Hastjarjo,D.,T.(2019). RancanganEksperimen-Kuasi. Buletin psikologi,27(2),187-203. Diunduh dari : https://jurnal.ugm.ac.id/buletinpsikologi

Maslim, Rusdi. (2013). Diagnosis Gangguan Jiwa, Rujukan Ringkas dari PPDGJ-III. Cetakan 2 Bagian Ilmu Kedokteran Jiwa FK-Unika Atmajaya. Jakarta: PT Nuh Jaya.

Suarni.,\& Darsana.,K. (1996). Pendekatan Konseling dan Psikoterapi. Naskah Publikasi, Fakultas Keguruan dan Ilmu Pendidikan Universitas Udayana Bali.

Susana.,T.(2015). Program Bantu Diri Terapi Kognitif Perilaku: Harapan bagi Penderita Depresi. Jurnal Psikologi, 42(1), 78-98. Diunduh dari : http://jurnal.ugm.ac.id

Sutarjo., A. 2005. Pengantar Psikologi Abnormal. PT. Refika Adit-ama Bandung.

Wiramihardja. (2005). Pengantar Psikologi Abnormal.Bandung: RefikaAditama.

Yaunin,Yaslinda.(2012). Gangguan Panik dengan Agorafobia. Majalah Kedokteran Andalas,2(36),235-243. Diunduh dari : http://jurnalmka.fk.unand.ac.id

Zainuri,I,M., \& Wulandari.,R,(2020). Studi Tentang Perilaku Agoraphobia Siswa dan Upaya Penanganannya. KONSELING: Jurnal Ilmiah Bimbingan dan Konseling, 1(2), 83-95. Diunduh dari : https://journal.ilininstitute.com/konseling 